\title{
Acquired Color Blindness
}

National Cancer Institute

\section{Source}

National Cancer Institute. Acquired Color Blindness. NCI Thesaurus. Code C118712.

Non-heritable difficulty in distinguishing colors. 